\title{
Acute alcohol effects on facial expressions of emotions in social drinkers: a systematic review
}

This article was published in the following Dove Press journal:

Psychology Research and Behavior Management

\section{Eva Susanne Capito \\ Stefan Lautenbacher \\ Claudia Horn-Hofmann}

Physiological Psychology, University of Bamberg, Bamberg, Germany
Correspondence: Eva Susanne Capito Physiological Psychology, University of Bamberg, 3 Markusplatz, Bamberg 96045, Germany

$\mathrm{Tel}+4995|863| 975$

Fax +49 95। 8631976

Email eva.capito@uni-bamberg.de
Background: As known from everyday experience and experimental research, alcohol modulates emotions. Particularly regarding social interaction, the effects of alcohol on the facial expression of emotion might be of relevance. However, these effects have not been systematically studied. We performed a systematic review on acute alcohol effects on social drinkers' facial expressions of induced positive and negative emotions.

Materials and methods: With a predefined algorithm, we searched three electronic databases (PubMed, PsycInfo, and Web of Science) for studies conducted on social drinkers that used acute alcohol administration, emotion induction, and standardized methods to record facial expressions. We excluded those studies that failed common quality standards, and finally selected 13 investigations for this review.

Results: Overall, alcohol exerted effects on facial expressions of emotions in social drinkers. These effects were not generally disinhibiting, but varied depending on the valence of emotion and on social interaction. Being consumed within social groups, alcohol mostly influenced facial expressions of emotions in a socially desirable way, thus underscoring the view of alcohol as social lubricant. However, methodical differences regarding alcohol administration between the studies complicated comparability.

Conclusion: Our review highlighted the relevance of emotional valence and social-context factors for acute alcohol effects on social drinkers' facial expressions of emotions. Future research should investigate how these alcohol effects influence the development of problematic drinking behavior in social drinkers.

Keywords: alcohol, alcohol effects, emotion, encoding, social drinking context, facial action

\section{Introduction}

It is both common sense and a corroborated finding of scientific research that alcohol affects emotions. ${ }^{1-8}$ In Western countries, where social drinking is common and well accepted, alcohol is expected to facilitate interpersonal communication by promoting positive and attenuating negative emotions. Alcohol is frequently exploited as a social lubricant, and improvement in social interaction is one of the most commonly reported motives for occasional alcohol consumption in social drinkers. ${ }^{5,9-12}$ Indeed, moderate alcohol consumption has been found to enhance positive emotions in social drinking contexts. $^{12,13}$ However, alcohol intake can also facilitate aggressive behavior, which might be due to negative effects of alcohol on impulse control. ${ }^{14-18}$ As such, alcohol has repeatedly been found to modulate behavior associated with both positive and negative emotions according to social context. 
In this review, we focus on expressions of emotions, due to their prominent role in social interaction. Facial expressions of emotions are an essential complement of verbal communication, as they validly reflect the subject's emotional state and thus convey the emotional content of a message. ${ }^{19-24}$ Simulated facial expressions of emotions can be distinguished from those of truly experienced emotions, due to subtle differences in patterns of facial activity. ${ }^{25}$ Moreover, both encoding (ie, display) and decoding (ie, recognition) of facial expressions of emotions are mostly immediate and automatic processes. ${ }^{26}$ Facial expressions thus enable quick information exchange, as often required in emotionally relevant situations. ${ }^{27,28}$ With the development of a systematic coding system by Ekman and Friesen that enabled the reliable measurement of facial activity, facial expressions became the most investigated component of nonverbal expressions of emotions. ${ }^{21,29,30}$

In this review, we focus exclusively on social drinkers for two reasons. First, we were interested in the effects of alcohol intake on nonverbal communicative behavior under nonpathological conditions, which seems highly relevant given the frequent consumption of alcohol at social events in Western cultures. Second, findings in patients with alcohol abuse or dependence are difficult to interpret, due to persisting cognitive and motor impairments and emotional difficulties in this group. ${ }^{31,32}$ Despite alcohol's ability to modulate expressions of emotions and despite the relevance of facial expressions of emotions for social interaction, we are the first to review alcohol effects on facial expressions of emotions in social drinkers.

\section{Heuristic model of alcohol effects on facial emotion processing}

To guide our literature search, we developed an heuristic model of alcohol effects on different stages of facial emotion processing (Figure 1). Our heuristic model posits alcohol effects on the emotional state, encoding of emotional state into facial motor programs, the inhibitory gate for facial expressions, and compliance with social display rules.

\section{Alcohol effects on emotional state}

Empirical evidence suggests that the consumption of an alcoholic beverage increases self-reported pleasurable moods, euphoria, and elation. ${ }^{14,5,8}$ In addition, slightly to moderately drunk individuals show a decrease in self-reported stress and anxiety. ${ }^{8,33-35}$ Moreover, alcohol attenuates startle potentiation in response to unpleasant stimuli, possibly by lowering threat appraisal. ${ }^{2-4,36}$ Nevertheless, alcohol has also been found to increase self-reported anger states, thus indicating an aggression-facilitating effect of alcohol. ${ }^{15,37}$ Giancola found that individual-trait anger mediated the relationship between alcohol intake and aggression. ${ }^{16}$

\section{Alcohol effects on encoding of emotional state into facial motor programs}

There is ample evidence that motor abilities deteriorate after alcohol intake. ${ }^{38-40}$ With regard to facial expressions, Dethier et al found that long-term alcohol abuse and alcohol addiction impaired performance when deliberately encoding facial expressions of emotions..$^{31,41}$ However, alcohol effects on

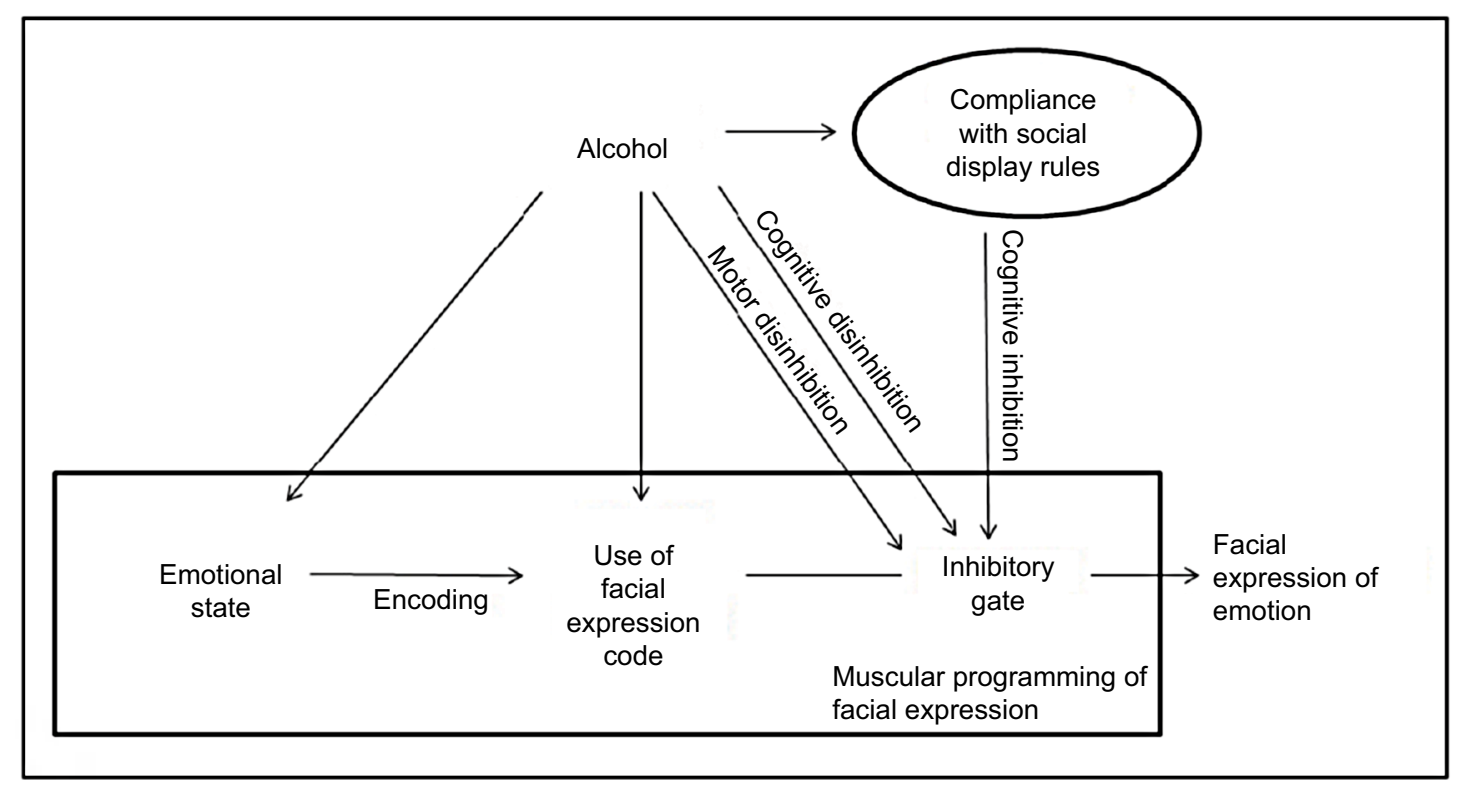

Figure I Heuristic model of facial emotion processing.

Notes: Rectangle indicates processes within individuals; ellipse denotes a social influence. 
deliberate encoding of facial expressions in social drinkers are (to our knowledge) not yet investigated.

\section{Alcohol effects on inhibitory gate for facial expressions}

It is assumed that before the motor expression of an affective state can be executed, the particular motor program has to pass an inhibitory gate specific for facial expressions. Alcohol effects on this inhibitory process seem likely, as disinhibiting alcohol effects on both a motor-inhibitory task performance and a cognitive-inhibitory task performance were reported by Rose and Duka. ${ }^{42}$ Moreover, an event-related brainpotential study found that after alcohol intake, individuals have to activate more cognitive resources to regulate and inhibit behavioral responses in both early and later stages of inhibitory control. ${ }^{43}$

\section{Alcohol effects on compliance with social display rules}

Social display rules include informal norms about when, where, and how emotions should be expressed, and are thought to moderate social nonverbal behavior, including facial expressions. ${ }^{44,45}$ Previous findings have suggested that alcohol might affect compliance with social display rules. First, as alcohol has been found to impair cognitive processes and inhibition, it possibly counteracts the inhibitory effect of social display rules. ${ }^{42,43}$ There is evidence that alcohol triggers increased nonverbal behavior that might usually be inhibited by social display rules in social drinking contexts. ${ }^{46}$ Second, alcohol consumption might reduce the perceived necessity to comply with social display rules. Indeed, slightly to moderately drunk individuals are commonly expected to show disinhibited nonverbal (emotional) behavior that is often not in accordance with social norms. ${ }^{17,42,43,47}$

In conclusion, we assume that alcohol exerts influence on facial expressions of emotions via different pathways. Based on these pathways, we developed our search algorithm for identifying relevant studies. Moreover, in our search for literature, we applied a broad working definition of emotions that is widely accepted, in spite of the variety of theoretical views and concepts. ${ }^{48}$ Accordingly, emotions are defined as temporary specific mental states of happiness, sadness, anger, anxiety, jealousy, pride, surprise, compassion, shame, guilt, envy, disappointment, relief, and mental states sufficiently similar to the emotions just mentioned. ${ }^{48}$ We limited our search to laboratory studies, as these provide higher controllability than field studies and enable the detection of potential underlying mechanisms of action. Furthermore, we selected investigations that studied evoked emotional expressions using well-defined experimental methods. Previous research has shown that both affective responses to alcohol and the display of facial expressions depend on the method "prompting the [emotional] response, and how strong its impact is on motives or emotions". 8,22 Moreover, we examined how sample characteristics as well as personality variables influence alcohol effects on facial expressions of emotions. Due to previously reported effects of sex, drinking history, and alcohol expectancy (ie, individual beliefs about how emotions, mood, and behaviors are affected by alcohol) on general subjective alcohol effects, we also assumed these variables to influence the effect of alcohol on facial expressions of emotions. . $^{73,49-52}$

Based on the aforementioned considerations, we developed the following hypothesis. We assumed that alcohol facilitates facial expressions of anger under aggressive provocation conditions, but also enhances facial expressions of positive emotions in innocuous drinking contexts. Additionally, we considered the role of sex, drinking history, and alcohol expectancy with regard to alcohol effects on facial expressions of emotions.

\section{Materials and methods}

The researchers prepared this review in compliance with the PRISMA (Preferred Reporting Items for Systematic Reviews and Meta-Analyses) guidelines for systematic reviews and meta-analysis. ${ }^{53}$

\section{Search algorithm}

We used the PRISMA flow diagram to present the selection of suitable publications (Figure 2) ${ }^{53}$ First, we scanned our selected online databases with a predefined search algorithm. Having removed duplicates, we reviewed the titles and abstracts of the retrieved results and extracted relevant publications that met our predetermined criteria as regards content and methodology. The detailed selection process is further described in the following paragraphs.

We searched for relevant empirical studies in the electronic databases PsycInfo, PubMed, and Web of Science (database selection was done according to similar systematic reviews dealing with alcohol effects on emotional parameters) ${ }^{54-56}$ within the overall time span covered by each database (from 1887, 1900, and 1926, respectively) until May 2017 in English and German languages. Considering our heuristic model of facial emotion processing (Figure 1), we applied the keywords "facial emotion encoding OR facial emotion inhibition OR nonverbal social behavior OR facial expression 


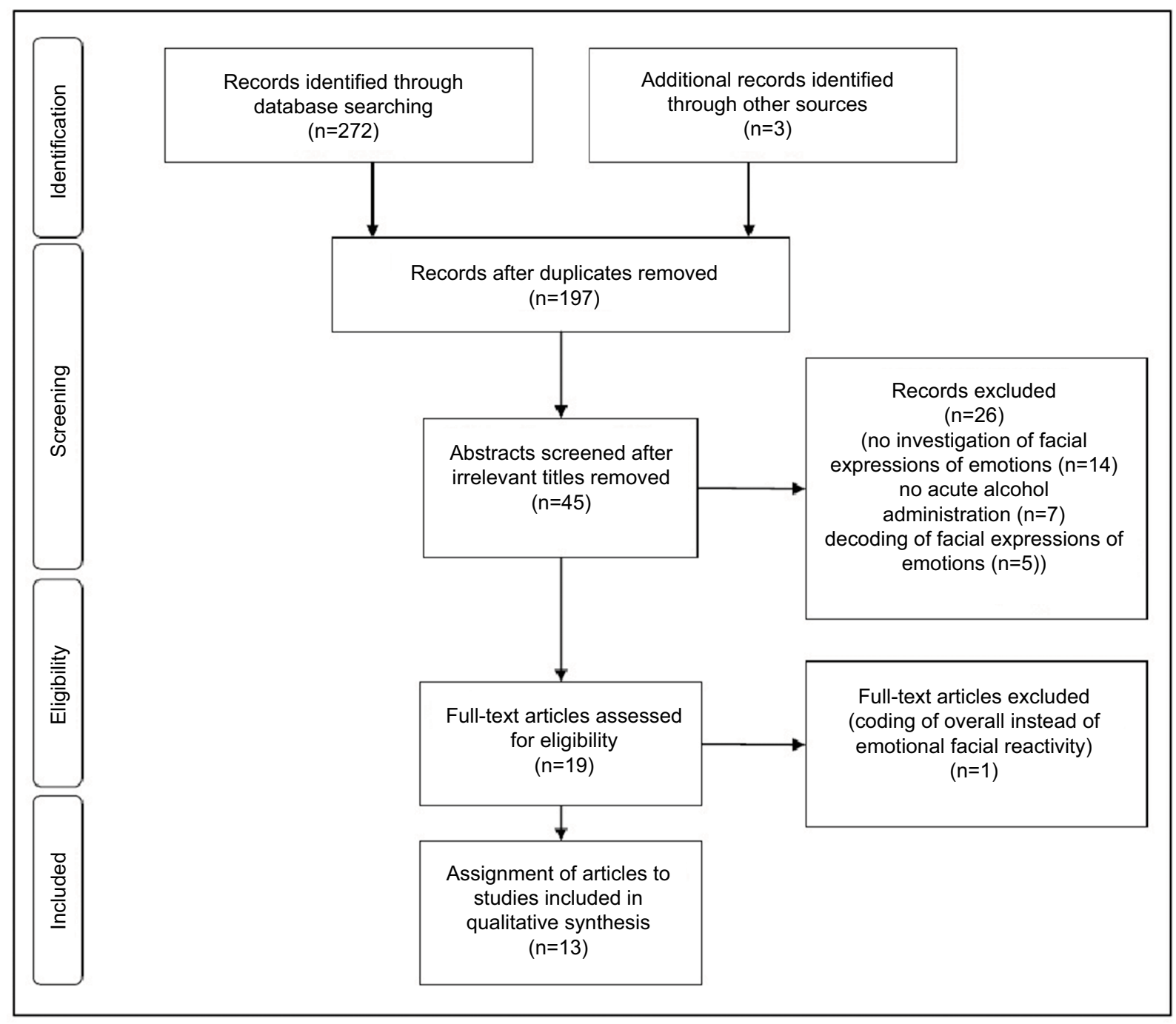

Figure 2 Process of study selection according to PRISMA flow diagram..$^{53}$

Abbreviation: PRISMA, Preferred Reporting Items for Systematic Reviews and Meta-Analyses.

of emotion" to our search. Additionally, we searched for studies that used objective measurements of facial expressions of emotions. Objective measurements do not only minimize the risk of observer-decoding bias within one investigation but also increase comparability between several investigations on alcohol effects on facial expressions of emotions. Facial actions can be assessed most objectively via electromyography (EMG) or via established psychometrical coding systems. We added the keywords "facial action coding OR facial electromyography" to our search algorithm. Finally, we combined ("AND") these keywords with "alcohol OR ethanol", and retrieved 383 articles published in English and one published in German. A brief glance at these search results revealed the inclusion of articles describing certain well-examined topics associated with alcohol effects on facial expressions that were, however, irrelevant for our review. Those articles focused on alcohol effects on facial emotion recognition, the influence of prenatal alcohol consumption on infants' facial expressions, and effects of pathological alcohol consumption. To exclude this literature, we narrowed our search algorithm using the "NOT" function ("NOT recognition NOT prenatal NOT pathologic"). This resulted in a total of 272 articles published in English that potentially suited the scope of our review. Moreover, we included three additional records previously identified through scanning reference lists.

Having excluded duplicates, the next step was conducted by two independent researchers in order to assure objectivity. This step consisted of the screening of both titles and abstracts of the obtained publications and the exclusion of those that appeared irrelevant for our review. In cases of disagreement, the researchers discussed their positions until they reached consensus. Deeper analysis of the remaining studies $(n=19)$ was done with regard to eight exclusion criteria we applied to our review. The empirical studies 1) had to be published in a 
peer-reviewed journal and 2) conducted on social drinkers in 3) laboratory settings. We included only investigations that used 4) systematic observations and recordings of 5) facial expressions of positive and negative emotions 6) induced by experimental methods. As observational studies can always imply the risk of the aforementioned observer bias, we only included studies with observer data that were either based 7) on established psychometrical coding systems for facial expressions (facial action coding system, maximally discriminative facial movement coding system) or 8) on selfdeveloped systematic coding rules with detailed observer instructions. ${ }^{29,57}$ According to this selection procedure and exclusion criteria, we identified 18 relevant publications with data derived from 13 primary studies (see Table 1 for the detailed assignment of publications to primary studies).

\section{Results and discussion}

In this section, we firstly review general characteristics, ie, sample characteristics, experimental control methods, and alcohol-administration characteristics, of the selected primary studies. Secondly, we describe and discuss acute alcohol effects on facial expressions of positive and negative emotions, whereby we used two perspectives. For the first perspective, we classified alcohol effects according to the valence of emotion expressed by the face. For the second perspective, we grouped these effects according to the level of social interaction implied in the study design. Thereby, we describe the methods to evoke and measure facial expression in more detail. As this systematized presentation of the data under these perspectives already goes beyond the mere presentation of results, we decided to combine results and discussion for better readability.

\section{General characteristics of studies reviewed}

From the primary studies selected, we retrieved information about general design, namely sample characteristics and experimental control methods (Table 1) and characteristics of alcohol administration (Table 2). We describe each of these study features first, and then discuss their effects on the relationship between alcohol and facial expressions of emotions (Tables 1-4).

\section{Sample characteristics}

Sample sizes in the 13 primary studies included in our review were 27-720 participants. Except for one study, which was conducted with panic-disorder patients, all samples consisted of healthy participants. ${ }^{58}$ In all but one investigation, participants were younger than 35 years. While eight of the studies were conducted with participants of both sexes, the others investigated either exclusively males $(n=3)$ or used all-female samples ( $\mathrm{n}=2$; see Table 1 for descriptive sample characteristics). Participants' drinking habits (Table 1) were assessed via self-report (eg, by psychometric questionnaires $[n=4])$ in all but one study. This study did not include any information about this topic, ${ }^{59}$ whereas two other studies provided very detailed reports of the subjects' drinking behavior. ${ }^{60,61}$

\section{Experimental control methods}

As shown in Table 1, we listed the control methods "placebo control", "baseline control", "blinding", and "randomization", which helped us to evaluate the methodical quality of the reviewed studies. Weaver et al considered only "randomization". ${ }^{59}$ Both control conditions and randomization were provided in two double-blind investigations and six single-blind investigations. ${ }^{58,60-68}$ The majority of studies used baseline control $(\mathrm{n}=10)$. Physiological measures during the testing, eg, recording of autonomous activation via heart/pulse rate or blood pressure, were considered rarely. ${ }^{62,63}$

The term "beverage group" describes the alcoholic or nonalcoholic beverage administered in a group of participants. Independently of this, drinkers can be either blinded or unblinded about the alcohol content of their beverages in a specific beverage group. While allocation to a specific beverage group was utilized as a between-subject factor (ie, each subject was allocated to one specific drinking group) in all investigations, only one study additionally compared the effect of different alcoholic and nonalcoholic drinks within subjects (beverage group as within-subject factor). There, subjects underwent two test sessions and were allocated to each drinking group once. ${ }^{60}$ In most of the studies $(n=10)$, participants were blinded to the content of their beverage. The assessment of alcohol expectancy (eg, via self-report) was neglected throughout. Figure 3 overviews the study protocols with regard to beverage groups and blinding.

\section{Alcohol administration}

We screened the studies with regard to the alcohol administered, the period of drink consumption (ie, the time subjects had to finish their drinks), and the time interval between drink consumption and the recording of facial expressions. Moreover, we extracted information on the assessment of breath-alcohol concentration (BAC) via spirometry. Alcoholadministration characteristics are reviewed in Table 2.

In all studies alcohol was administered orally, the dose was adjusted to the subjects' body weight, and (if reported) 


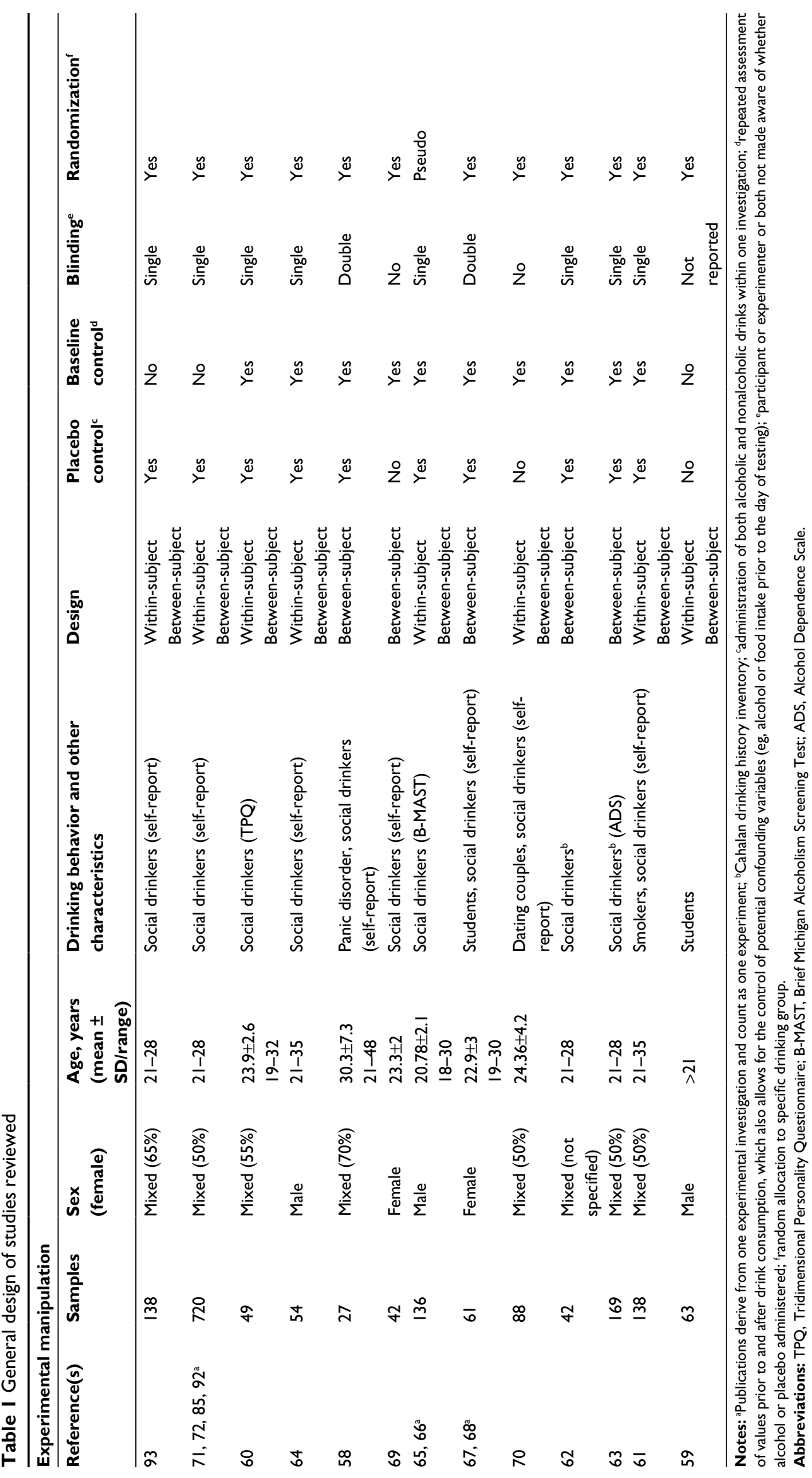




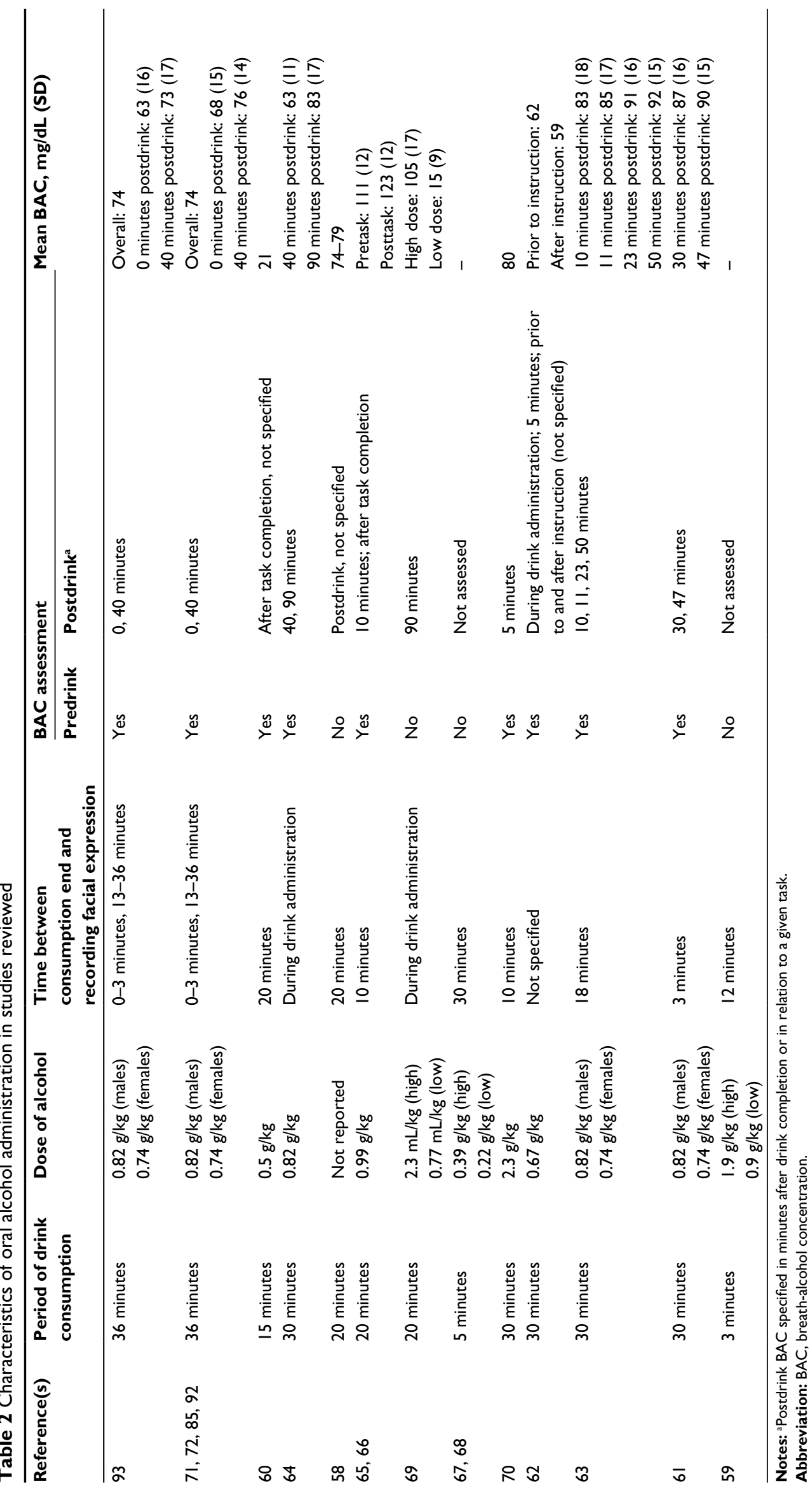




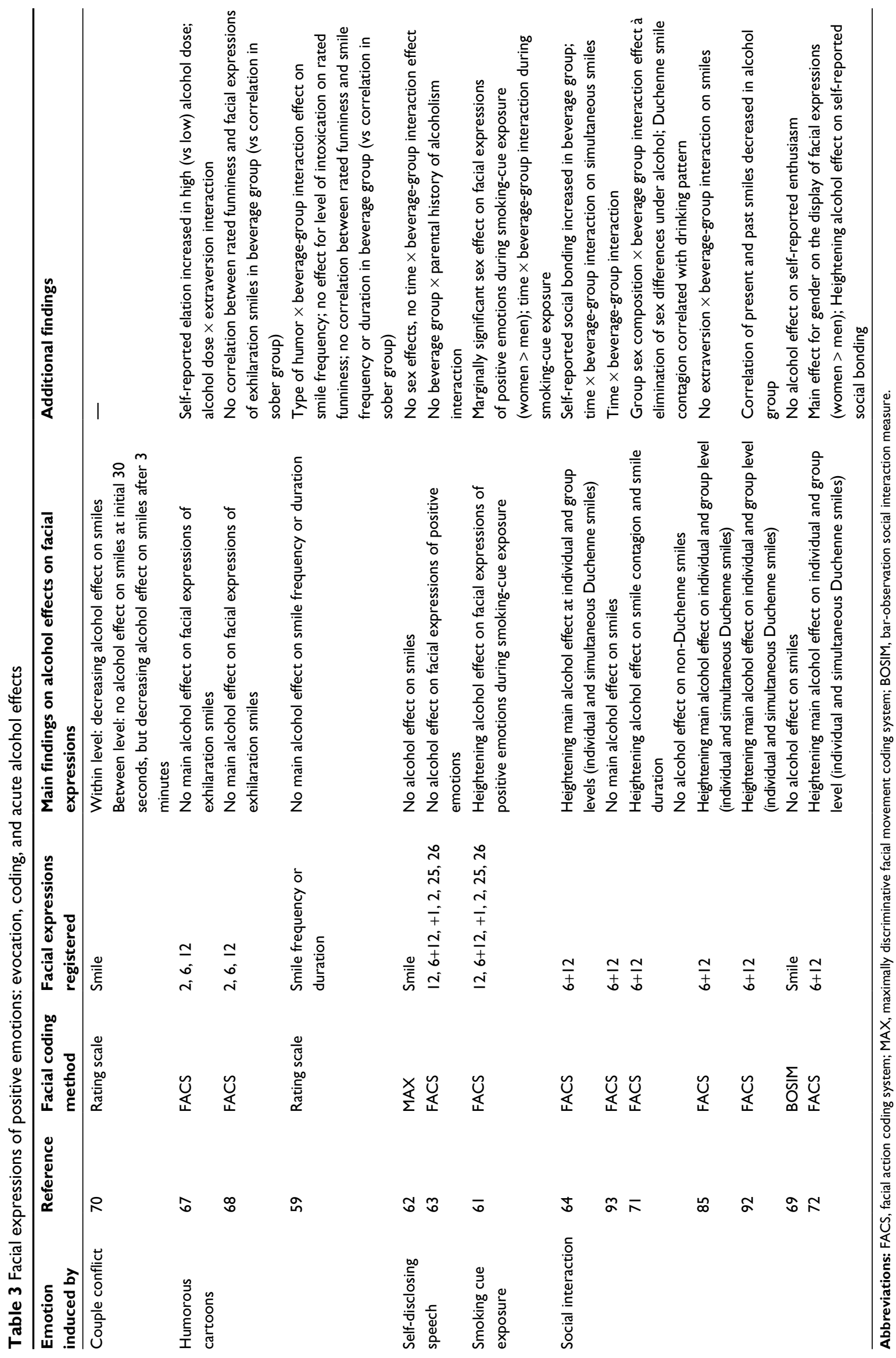


ranged from $0.22 \mathrm{~g} / \mathrm{kg}$ to $2.3 \mathrm{~g} / \mathrm{kg}$ body weight. Only three studies administered a dose higher than $1 \mathrm{~g} / \mathrm{kg}$ body weight. ${ }^{59,69,70}$ Kushner et al administered variable alcohol doses to achieve a targeted BAC ${ }^{58}$ Two (low vs high) alcohol doses were compared for their effects on facial expressions of emotions in three studies included in our review.

Manipulation checks were accomplished by assessing subjective intoxication ratings $(n=11)$ or postdrink breath alcohol measures $(n=11)$. Predrink BACs were assessed in most studies $(n=10)$. Repeated measurement of postdrink BACs to track blood-alcohol levels over time was included in seven studies. Facial expressions were recorded within different time frames ( 0 -36 minutes) after drink completion. One study failed to report the time frame of recording. ${ }^{62}$

Information on the period of drink consumption was provided by all studies but one. However, there was considerable heterogeneity regarding this period: 3-36 minutes. In order to increase comparability between studies with regard to alcoholadministration characteristics, we related the dose of alcohol $(\mathrm{g} / \mathrm{kg})$ to the time allowed for drink consumption (minutes). As such, the highest doses of alcohol related to the time for drink consumption were found in Weaver et al: ${ }^{59} 0.63 \mathrm{~g} / \mathrm{kg}$ per minute (high dose) and $0.3 \mathrm{~g} / \mathrm{kg}$ per minute (low dose). This was followed by doses of $0.04-0.12 \mathrm{~g} / \mathrm{kg}$ per minute in four studies included in our review. ${ }^{65-70}$ In the remaining studies $(\mathrm{n}=7)$ the ratio was from $0.02-0.03 \mathrm{~g} / \mathrm{kg}$ per minute.

\section{Effects of general study characteristics on relationship between alcohol and facial expressions of emotions}

Regarding sample characteristics, sex effects on facial expressions of emotions after alcohol intake were analyzed in four studies (Tables 3 and 4), and yielded inconsistent results. ${ }^{60-62,71,72}$ Two studies reported no effects of sex, whereas the others indicated a higher occurrence of facial expressions of positive (Table 3 ) and negative (Table 4) emotions in women independently of alcohol intake.

These findings suggest that alcohol does not diminish preexisting sex differences in facial expressions of emotions, which are commonly reported: Men are not only found to be generally less expressive than women but also to show different expressions, eg, more facial expressions interpreted as signs of pride and power, more facial expressions of anger, and fewer smiles compared to women. ${ }^{73-78}$ In one of the reviewed studies, alcohol led to disappearance of sex differences in smile contagion, an effect that consists in the spread of smiling within a social group. ${ }^{71}$ Sober all-male groups showed less smile contagion than sober mixed-sex groups; these differences vanished after alcohol consumption. This effect was not driven by the sex of the smile initiator, but by the sex of the person who received the smile.

Modulatory effects on facial expressions after alcohol intake by drinking pattern and drinking history were sparsely analyzed in the studies included in our review $(n=2)$. In both studies, the authors found no significant differences in facial expressions under acute intoxication between lightand heavy-drinking groups. In one of these studies, there was only a trend toward heightened musculus corrugator activity (which indicates negative affect) in heavy drinkers (Table 4). ${ }^{60}$ Previous research has found that light drinkers report increased sedation but also more aversive alcohol effects than moderate/heavy drinkers. ${ }^{8,49}$ Therefore, it seems that differences in subjective alcohol effects between light and heavy drinkers are not necessarily reflected in different facial expressions of emotion. With regard to experimental control methods, participant blindness is crucial in order to minimize the impact of alcohol expectancy. ${ }^{9,17,18,47,50}$ Alcohol expectancy was not studied in our review, but has previously been found to influence (light vs heavy) drinking behavior. ${ }^{51,79,80}$

With regard to alcohol-administration characteristics, none of the reviewed studies considered different effects that may occur during the ascending and descending limb of the BAC curve. However, this might be of relevance, as previous research has indicated that similar alcohol concentrations produce positive and stimulating effects on the ascending limb, but depressant effects on the descending limb. ${ }^{52,81-83} \mathrm{An}$ EMG study by Pishkin et al demonstrated such differences between the ascending and descending limbs with regard to overall facial activity. ${ }^{84}$ Compared to sober individuals, intoxicated participants showed more facial activity on the ascending limb after failure (negative emotion) and more activity on the descending limb after success (positive emotion). This finding suggests that pharmacokinetic properties determine alcohol effects on the facial expression of emotion.

In conclusion, despite their general relevance for subjective alcohol effects, the variables sex, drinking pattern, drinking history, and alcohol expectancy were (if at all) only sparsely analyzed in the reviewed studies. A such, their modulating effects on alcohol effects on facial expressions of emotions cannot be clarified by our review, and should be a topic in future research.

\section{Alcohol effects on facial expressions of emotions}

In order to provide a clearly arranged overview of the findings concerning acute alcohol effects on facial expressions 


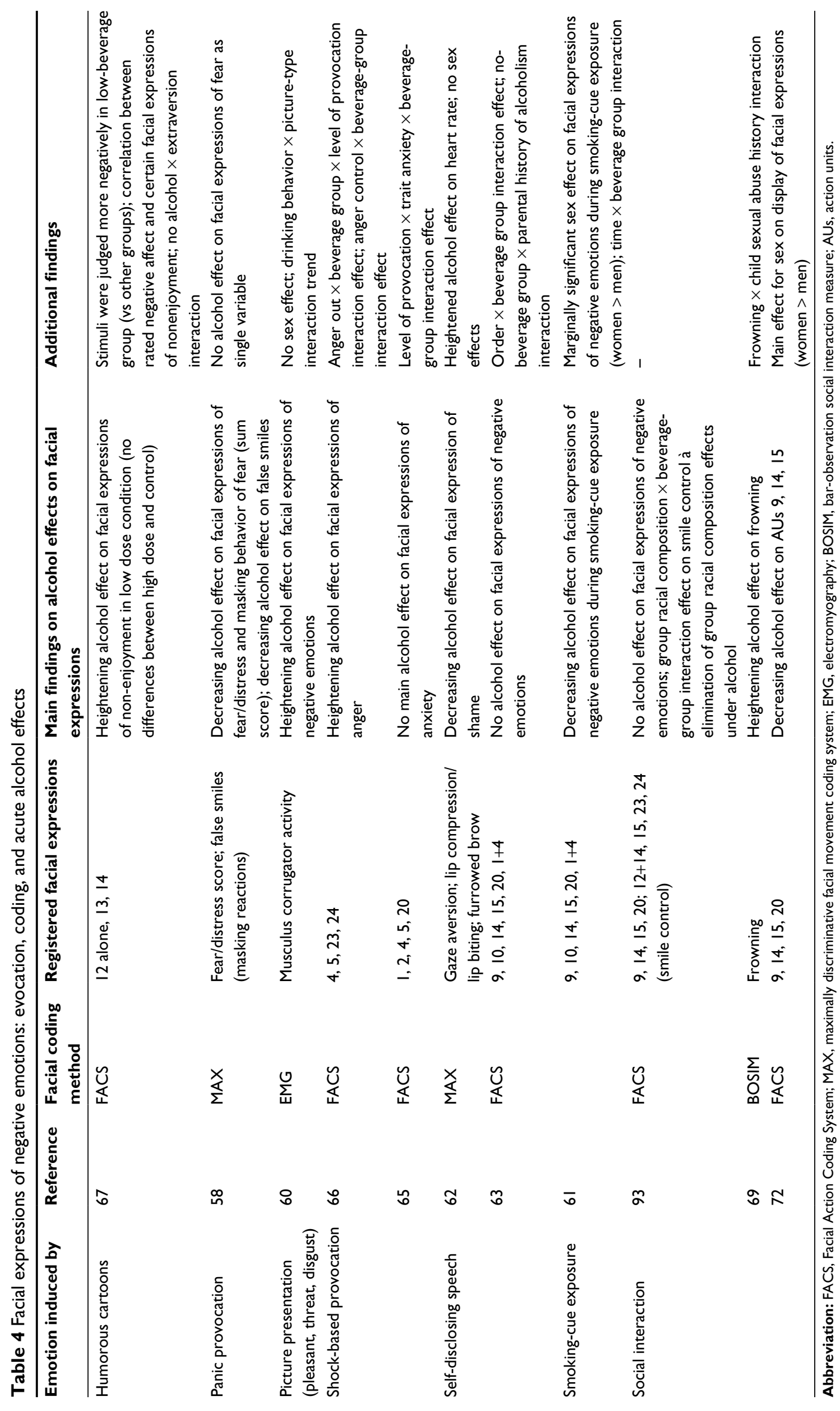




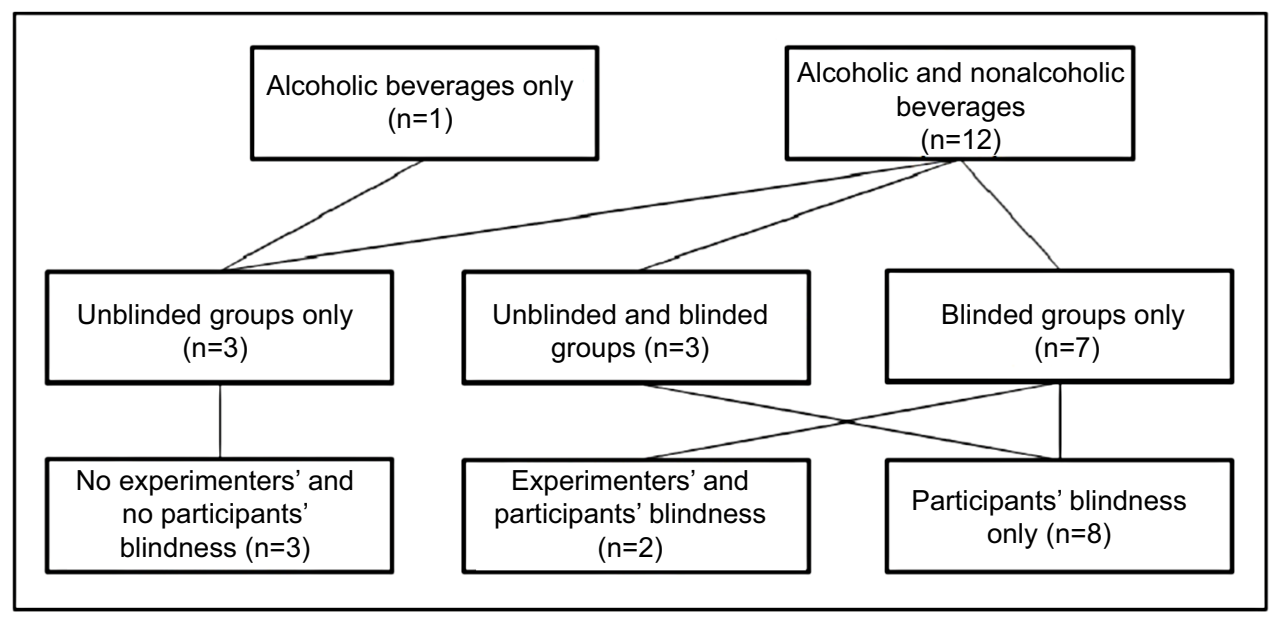

Figure 3 Experimental control methods for different beverage groups according to the study protocols.

of emotions, results were categorized in facial expressions of positive (Table 3 ) and negative (Table 4) emotions. Both general and dose-dependent alcohol effects are summarized. Thereafter, we review and discuss alcohol effects on facial expressions of emotions dependent on the level of social interaction imposed by the study design. We provide further information about study-design characteristics and particularly refer to the evocation and coding of facial expressions of emotions.

\section{General alcohol effects}

With regard to facial expressions of positive emotions, eight studies found no change after alcohol intake, whereas six other studies reported an increase in expressivity. Only one study reported a decrease in facial expressions of positive emotions after drinking. ${ }^{70}$ For negative emotions, we identified an almost equal number of studies suggesting unaffected $(n=3)$, increased $(n=4)$, and decreased $(n=6)$ facial expressions during intoxication.

\section{Dose-dependent alcohol effects}

Weaver et al did not find any dose-dependent alcohol effects on facial expressions of negative emotions; other studies reported increased or decreased facial expressions of negative emotions in high- compared to low-intoxication groups. . $9,67,69^{-1}$ Moreover, interaction effects between level of intoxication and method of emotion induction on facial expressions of enjoyment occurred. According to this, the higher the alcohol level, the fewer smiles elicited by subtle humor; in contrast, there were no alcohol-dose effects on smiles elicited by blunt humor. ${ }^{59}$ Ruch reported interaction effects between the level of intoxication and extraversion on facial expressions of enjoyment: ${ }^{67}$ the higher the alcohol level, the fewer smiles displayed by extraverts; there was no alcohol-dose effect on smiles in introverts. In contrary, Fairbairn et al did not find any interaction effects between alcohol level and extraversion on facial expressions of positive emotions. ${ }^{85}$

Overall, these inconsistent findings corroborated the assumption that there are crucial moderating variables with regard to alcohol effects on facial expressions of emotions. ${ }^{17,86}$ We have already considered pathways moderating how alcohol exerts influence on facial expressions of emotions (Figure 1). One prominent factor included in our model was social interaction. In general, social interaction comprises communicative behavior between different actors who reciprocally respond to each other, and influence or direct each other. ${ }^{87}$ The level of social interaction depends on different factors, eg, the number of interaction partners and the type of interaction (direct vs indirect, face to face vs virtual). The term "social drinkers", which is commonly used for individuals who show a pattern of occasional, nonpathological alcohol consumption, already points to the relevance of social factors for drinking behavior in this group. Moreover, there is evidence that both the emotional response to alcohol (eg, more stimulating alcohol effects in the presence of a drinking partner vs drinking alone) and the display of facial expressions of emotions vary with the social context. ${ }^{7,8,13,22,88}$ Therefore, we grouped the studies according to the level of social interaction imposed by the study design into those with low, moderate, and high levels of social interaction. With regard to the communicative function of nonverbal behavior, we assumed alcohol effects on facial expressions of emotions to increase with an increasing level of social interaction. ${ }^{24}$ 
Alcohol effects on facial expressions of positive and negative emotions considering level of social interaction

We defined low-level social interaction contexts as situations in which participant attention is focused on a specific task that does not include direct social interaction. We assumed a moderate level of social interaction to be present in the studies in which participants were asked to deliver a videotaped speech about what they liked and disliked about their physical appearance. This assumption is based on the fact that participants addressed their speech to an indirect (virtual) but specified interaction partner. In the studies reviewed, the addressee was a group of psychology students. Contexts including face-to-face communication with at least one interaction partner were classified as high-level social interaction.

We found six primary studies that used a low level of social interaction. In four of these studies, the experimenters merely observed the participants during the experimental task, which consisted in the judgment of emotional pictorial stimuli or exposure to smoking cues..$^{59-61,67,68}$ In two other studies, the participants underwent a panic provocation or received electric shocks during the absence of the experimenters, who administered the stimuli from a separate room and observed task performance by using video surveillance. ${ }^{58,65,66}$

Alcohol intake did not exert any effect on the facial expression of positive emotions (enjoyment) elicited by humorous stimuli (Table 3). ${ }^{59,67,68}$ Moreover, an alteration of alcohol-dose level (high vs low) did not affect facial expressions of exhilaration in these studies. Participants who had consumed alcohol showed more frequent facial expressions of negative emotions in response to humorous stimuli than sober individuals (Table 4) ${ }^{60,67}$ Ruch reported increased facial expressions of negative emotions for only a low (vs high) alcohol dose. ${ }^{67}$ Glautier et al found heightened EMG musculus corrugator activity, which is considered an indicator of negative affect after alcohol consumption, while watching pleasant, threat-related and disgust-related pictures..$^{60,89}$ Therefore, in social drinkers who judged pictorial stimuli in settings with low levels of social interaction, alcohol merely showed increasing effects on facial expressions of negative emotions. It is of note that this effect occurred for both pleasant and unpleasant pictorial stimuli.

Sayette et al investigated the effect of alcohol on facial expressions of emotions that occurred during cigarette craving (12-hour smoking abstinence) in heavy smokers. ${ }^{61}$ They found that during exposure to smoking cues (presentation of a lit cigarette), alcohol increased facial expressions of positive emotions (Table 3 ) and marginally decreased the occurrence of facial expressions of negative emotions; however, this effect declined over time (Table 4). ${ }^{61}$ Previous research by Sayette et al suggested that a smoker's facial expression of positive emotions during cigarette craving indicates an increased likelihood of initiating smoking. ${ }^{90}$

In a study by Kushner et al conducted on panic patients, slightly to moderately drunk participants showed decreased facial expressions of fear/distress, as well as less active facial behavior to suppress these signs under panic provocation (Table 4). ${ }^{58}$ These findings can be interpreted in the context of previous findings of alcohol attenuating panic symptoms. ${ }^{2,4}$

Regarding healthy participants under provocation by electric shock (Table 4), there is evidence for an alcoholdependent increase in the facial expression of anger, but no main effect of alcohol on facial expressions of anxiety. ${ }^{65,66}$ Alcohol enhanced the relationship between the individual's actual facial expression of emotion and his or her trait anger or trait anxiety under certain levels of provocation (implemented by the intensity of electric shocks). Particularly, under alcohol, trait anger evoked facial expressions of anger under high provocation (ie, high-intensity shocks), and the increase in facial expressions of anxiety occurred only in highly anxious men under low provocation (ie, low-intensity shocks). ${ }^{65,66}$ These results were corroborated by other findings highlighting the influence of both aggression-related traits and provocation level on anger expression. ${ }^{14-18}$

In two of the studies reviewed, we found a moderate level of social interaction. ${ }^{62,63}$ These studies, in which participants delivered a videotaped self-disclosing speech, reported no alcohol effects on the facial expression of positive emotions (Table 3). Alcohol decreased facial expressions of negative emotions in both studies (Table 4); however, in one of the studies this effect depended on whether the stressor was introduced before or after alcohol administration. ${ }^{63}$ Also in the latter study, signs of fear and anger suppression measured by lip compression and lip biting were heightened within slightly to moderately drunk individuals in contrast to their sober counterparts. Alcohol was previously found to modulate signs of negative emotions visible in the face during delivering a speech. Particularly, Stevens et al found decreased facial blushing after alcohol intake and thus highlighted the functional advantage of reduced (facial) signs of nervousness that increased the speakers' self-confidence and reduced social anxiety. ${ }^{91}$

Contexts with high-level social interaction were identified in five studies. ${ }^{59,61,72,79,80,85,92,93}$ In general, the process of group formation among unacquainted participants is commonly used in experimental paradigms aimed at investigating social 
context effects. Both positive and negative emotional states can equally be evoked by group formation. ${ }^{7}$ Moreover, it is possible simultaneously to observe (facial) behavior on individual (reactions of one individual, eg, smiling) and group levels (simultaneous reactions of several individuals, eg, smile contagion) in this context.

Alcohol effects on smile behavior at both individual and group levels were found in three studies using the groupformation paradigm (Table 3). ${ }^{64,71,72,85,92,93}$ Fairbairn et al measured fewer smile controls, ie, facial expressions that counteract an occurring smile, under alcohol (Table 4), but no alcohol effects on facial expressions of positive and negative emotions themselves. ${ }^{93}$ In another study, alcohol (vs placebo) decreased facial expression of negative emotions (Table 4). ${ }^{72}$

In sum, within the process of group formation, alcohol consumption heightened the frequency of positive facial expressions and smile contagion, and at least partially decreased facial expressions of negative expressions. In a simulated couple-conflict situation, slightly to moderately drunk individuals showed significantly less positive facial expressions relative to their sober counterparts and a decline in expressing positive emotions over time (Table 3 ). ${ }^{70}$ This might indicate that individuals can play their allocated role as conflict partner in a more authentic way after alcohol intake. In other words, slightly to moderately drunk individuals acted more as expected, ie, they performed more socially desirably, considering the given task. Summarizing alcohol effects on facial expressions of emotions in situations with a high level of social interaction, we conclude that moderate dosages of alcohol affect both positive and negative facial expressions in a way that increases desirable social behavior. Moreover, since alcohol also seems to dampen smile-control expressions, a further argument for the function of alcohol as social lubricant is available. In general, mood- and social bond-enhancing alcohol effects can be explained by a "social-attributional" approach, whereby alcohol interferes with the anticipation and elaboration of social rejection. ${ }^{86}$ Alternatively, these effects might also be explained by so-called alcohol myopia, which describes a narrowing of perception and cognition by alcohol that temporarily alleviates worries and causes a feeling of relief..$^{35,92}$ Further exploratory approaches on how alcohol affects emotions in social drinkers are elaborately discussed in a recent review by Sayette. ${ }^{7}$

Increasing BACs, however, do not seem to enhance these effects, as shown by Parks et al (Tables 3 and 4). ${ }^{69}$ In this study, increases in the administered alcohol dose (paralleled by increases in BAC) did not affect facial expressions of positive emotions but increased facial expressions of negative emotions.

\section{Limitations}

In the following, we briefly discuss limitations of this review. Moreover, we summarize limitations of the studies reviewed and provide suggestions for future research.

\section{Limitation of this systematic review}

In order to review alcohol effects on the facial expression of emotions in social drinkers, we categorized studies according to the level of social interaction imposed by the study design. There are also other factors given by our heuristic model of facial emotion processing (Figure 1) to organize the present review. However, we chose the level of social interaction, because we assumed it to be one of the most important moderating variables in this context and also for the pragmatic reason that all reviewed studies provided information on the level of social interaction, whereas this information would not have been available for the other variables included in our heuristic model.

\section{Limitations of studies reviewed and suggestions for future research}

There are also some limitations of the studies reviewed, each highlighting directions for future research. First, alcohol effects on facial expressions of anger and anxiety were assessed only in male participants. ${ }^{65,66}$ Due to pronounced sex differences in both facial expressions and aggression, generalization of these effects to female participants is not possible, and future studies should also investigate female samples. ${ }^{16,73-78,94,95}$ Second, the studies reviewed considered various emotions that are encoded into specific facial expressions. In order to enhance comparability of the studies, future research should refer to similar concepts of emotions; we propose using a broad working definition of emotion. ${ }^{48}$ Moreover, there is to date no experimental investigation dealing with alcohol effects on facial expressions of sadness. However, such effects can be expected due to mood-enhancing and stress-dampening effects of alcohol, and should thus be examined in future research.?

Third, the studies included in our review did not compare alcohol effects on facial expressions of emotions that appear on the ascending or descending limb of the BAC curve. However, since the same alcohol concentration often exerts different subjective effects (stimulating vs depressant) on the ascending vs descending limb of the BAC curve, this seems to be an important topic to be considered in future 
studies. ${ }^{52,83}$ Fourth, in one study, facial muscle activity was measured via EMG using surface electrodes. ${ }^{60}$ Despite the high objectivity of this method, the spatial resolution is not good enough to distinguish fully among expressions of different emotions. Indeed, only musculus corrugator and zygomaticus activity are commonly interpreted as measures of negative and positive emotions, respectively. The use of needle electrodes would improve spatial resolution, but may irritate. The application of electrodes always leads to artificial conditions, possibly changing facial expressions. For a comprehensive analysis and interpretation of facial activity, we recommend an additional observer rating to distinguish among different kinds of emotion expressions. Concordance of EMG-recorded facial activity with observer ratings would facilitate the interpretation of certain patterns of EMG facial activity as indicative of the expression of specific emotions.

Fifth, a potential interaction between social context factors and the method used for emotion induction has not yet been studied, but might be considered. For example, emotion induction via picture presentation and anger provocation are confounded with low-level social interaction contexts. ${ }^{59,60,65-68}$ Sixth, as already discussed, sex effects, the subjects' drinking history, and alcohol expectancy have been sparsely investigated. Due to their importance for the relationship between alcohol and emotion, however, they should be considered systematically in future investigations. Seventh, no examination of alcohol effects on the facial expression of pain has yet been conducted. There is an established relationship between alcohol consumption and clinical pain: individuals suffering from pain tend to consume more alcohol, and individuals presenting with alcohol abuse often report pain symptoms. ${ }^{96,97}$ In addition, pain-dampening effects of alcohol could be proven experimentally. ${ }^{55,98}$ Moreover, there is a close relationship between emotion and pain: modulating effects of emotional stimuli on pain perception have been repeatedly reported. ${ }^{99-103}$ In sum, due to close mutual relationships among alcohol, emotion, and pain, we would expect to find alcohol effects also on the facial expressions of pain.

\section{Conclusion}

Despite the common use of alcohol to modulate emotion, there is still little systematic research on alcohol effects on the facial expression of emotions. As we tried to demonstrate with our heuristic model (Figure 1), alcohol can potentially impact facial expressions of emotion on various stages. To date, our review is the first approach to systematize the available literature on this research topic.
Overall, alcohol exerts effects on facial expressions of emotions in social drinkers. These effects are not generally disinhibiting, but vary depending on the valence of emotion and on social interaction. In moderate- and high-level social interaction, alcohol mostly influences facial expressions in a socially desirable way, thus underscoring the view of alcohol as social lubricant. Important research gaps to be closed by future studies are the investigation of alcohol effects on the facial expressions of sadness and pain, as well as the consideration of potential moderating variables (eg, alcohol expectancy). Future research should also investigate if socially desirable alcohol effects on facial expressions trigger increased drinking and thus might influence the development of problematic drinking behavior in social drinkers.

\section{Acknowledgments}

We thank the Ständige Kommission für Forschung und wissenschaftlichen Nachwuchs (FNK) and the Deutsche Forschungsgemeinschaft (DFG) for funding the related research projects “020624 Die akute Wirkung von Alkohol auf die Schmerzverarbeitung [Acute alcohol effects on pain processing]" and "GZ: HO 5573/1-1 Trinken gegen Schmerz? Physiologische und psychologische Wirkmechanismen von Alkohol auf die Schmerzwahrnehmung [Drinking against pain? Physiological and psychological effect mechanisms of alcohol on pain perception]", which inspired the authors to perform this review.

\section{Disclosure}

The authors report no conflicts of interest in this work.

\section{References}

1. aan het Rot M, Russell JJ, Moskowitz DS, Young SN. Alcohol in a social context: Findings from event-contingent recording studies of everyday social interactions. Alcohol Clin Exp Res. 2008;32(3):459-471.

2. Donohue KF, Curtin JJ, Patrick CJ, Lang AR. Intoxication level and emotional response. Emotion. 2007;7(1):103-112.

3. Donohue KF, Lang AR, Patrick CJ. Alcohol and emotions: potential dose effects and mechanisms of neuromuscular control. Alcohol Clin Exp Res. 2003;27 Suppl 5:136A.

4. Levenson RW. Alcohol, affect, and physiology: positive effects in the early stages of drinking. In: Gottheil E, Druley K, Pasko S, Weinstein S, editors. Stress and Addiction. New York: Bruner/Mazel; 1987:173-196.

5. Miller MA, Bershad AK, de Wit H. Drug effects on responses to emotional facial expressions: recent findings. Behav Pharmacol. 2015;26(6):571-579.

6. Oscar-Berman M, Marinković K. Alcohol: effects on neurobehavioral functions and the brain. Neuropsychol Rev. 2007;17(3):239-257.

7. Sayette MA. The effects of alcohol on emotion in social drinkers. Behav Res Ther. 2017;88:76-89.

8. Smith RC, Parker ES, Noble EP. Alcohol and affect in dyadic social interaction. Psychosom Med. 1975;37(1):25-40.

9. Cooper ML, Frone MR, Russell M, Mudar P. Drinking to regulate positive and negative emotions: a motivational model of alcohol use. J Pers Soc Psychol. 1995;69(5):990-1005. 
10. Cox WM, Klinger E. Incentive motivation, affective change, and alcohol use: a model. In: Cox WM, editor. Why People Drink. New York: Gardner Press; 1990:291-314.

11. Goldman MS, Brown SA, Christiansen BA. Expectancy theory: thinking about drinking. In: Blane HT, Leonard KE, editors. Psychological Theories of Drinking and Alcoholism. New York: Guilford; 1987:181-226.

12. Monahan JL, Lannutti PJ. Alcohol as social lubricant. Hum Commun Res. 2000;26(2):175-202.

13. Pliner P, Cappell H. Modification of affective consequences of alcohol: a comparison of social and solitary drinking. J Abnorm Psychol. 1974;83(4):418-425.

14. Anderson CA, Bushman BJ. Human aggression. Annu Rev Psychol. 2002;53:27-51.

15. Chermack ST, Giancola PR. The relation between alcohol and aggression: an integrated biopsychosocial conceptualization. Clin Psychol Rev. 1997;17(6):621-649.

16. Giancola PR. The influence of trait anger on the alcohol-aggression relation in men and women. Alcohol Clin Exp Res. 2002;26(9):1350-1358.

17. Hull JG, Bond CF. Social and behavioral consequences of alcohol consumption and expectancy: a meta-analysis. Psychol Bull. 1986;99(3):347-360.

18. Zhang L, Welte JW, Wieczorek WW. The role of aggression-related alcohol expectancies in explaining the link between alcohol and violent behavior. Subst Use Misuse. 2002;37(4):457-471.

19. Darwin C. The Expression of the Emotions in Man and Animals. London: John Murray; 1872.

20. Ekman P, Rosenberg EL. What the Face Reveals: Basic and Applied Studies of Spontaneous Expression using the Facial Action Coding System (FACS). New York: Oxford University Press; 1997.

21. Mees U. Zum Forschungsstand der Emotionspsychologie - eine Skizze [Regarding current research in emotion psychology - an outline]. In: Schützeichel R, editor. Emotionen und Sozialtheorie. Frankfurt: Campus; 2006:104-123.

22. Parkinson B. Do facial movements express emotions or communicate motives? Pers Soc Psychol Rev. 2005;9(4):278-311.

23. Sokolowski K. Emotion. In: Müsseler J, Prinz W, editors. Lehrbuch Allgemeine Psychologie. Heidelberg: Spektrum Akademischer Verlag; 2002:337-384. German.

24. Watzlawick P, Beavin JH, Jackson DD. Pragmatics of Human Communication: A Study of Interactional Patterns, Pathologies, and Paradoxes. New York: WW Norton; 2011.

25. Ekman P. Expression or communication about emotion? In: Segal GE, Weisfeld CC, editors. Uniting Psychology and Biology: Integrative Perspectives on Human Development. Washington: American Psychological Association; 1997:315-338.

26. Blair RJ. Facial expressions, their communicatory functions and neuro-cognitive substrates. Philos Trans $R$ Soc Lond B Biol Sci. 2003;358(1431):561-572.

27. Dimberg U. Facial electromyography and the experience of emotion. J Psychophysiol. 1988;(3):277-282.

28. Shariff AF, Tracy JL. What are emotion expressions for? Curr Dir Psychol Sci. 2011;20(6):395-399.

29. Ekman P, Friesen WV. Facial Action Coding System: A Technique for the Measurement of Facial Movement. Palo Alto (CA): Consulting Psychologists Press; 1978.

30. Keltner D, Ekman P. Facial expression of emotion. In: Lewis M, Haviland-Jones J, editors. Handbook of Emotions. 2nd ed. New York, NY: Guilford Publications; 2000:236-249.

31. Dethier M, Douws L, Blairy S. Cognitive and emotional empathy in alcohol-dependent patients (ADs): a review of the literature. Rev Francoph Clin Comport Cogn. 2011;16(2):1-36.

32. Sullivan EV, Rosenbloom MJ, Pfefferbaum A. Pattern of motor and cognitive deficits in detoxified alcoholic men. Alcohol Clin Exp Res. 2000;24(5):611-621.

33. Hendler RA, Ramchandani VA, Gilman J, Hommer DW. Stimulant and sedative effects of alcohol. In: Sommer WH, Spanagel R, editors. Behavioral Neurobiology of Alcohol Addiction. Heidelberg: Springer; 2011:489-509.
34. Sayette MA. An appraisal-disruption model of alcohol's effects on stress responses in social drinkers. Psychol Bull. 1993;114(3):459-476.

35. Steele CM, Josephs RA. Drinking your troubles away - II: an attentionallocation model of alcohol's effect on psychological stress. J Abnorm Psychol. 1988;97(2):196-205.

36. Curtin JJ, Patrick CJ, Lang AR, Cacioppo JT, Birbaumer N. Alcohol affects emotion through cognition. Psychol Sci. 2001;12(6):527-531.

37. Bushman BJ, Cooper HM. Effects of alcohol on human aggression: an integrative research review. Psychol Bull. 1990;107(3):341-354.

38. Brumback T, Cao D, King A. Effects of alcohol on psychomotor performance and perceived impairment in heavy binge social drinkers. Drug Alcohol Depend. 2007;91(1):10-17.

39. Fogarty JN, Vogel-Sprott M. Cognitive processes and motor skills differ in sensitivity to alcohol impairment. J Stud Alcohol. 2002;63(4):404-411.

40. King AC, Byars JA. Alcohol-induced performance impairment in heavy episodic and light social drinkers. J Stud Alcohol. 2004;65(1):27-36.

41. Dethier M, El Hawa M, Duchateau R, Blairy S. Emotional facial expression recognition and expressivity in type I and type II alcohol dependent patients. J Nonverbal Behav. 2014;38(1):89-105.

42. Rose AK, Duka T. The influence of alcohol on basic motoric and cognitive disinhibition. Alcohol Alcohol. 2007;42(6):544-551.

43. Euser AS, Franken IH. Alcohol affects the emotional modulation of cognitive control: an event-related brain potential study. Psychopharmacology. 2012;222(3):459-476.

44. Siegler R. How Children Develop. New York: Worth Publishers; 2006.

45. Zaalberg R, Manstead A, Fischer A. Relations between emotions, display rules, social motives, and facial behaviour. Cogn Emot. 2004;18(2): 183-207.

46. Steele CM, Southwick L. Alcohol and social behavior - I: the psychology of drunken excess. J Pers Soc Psychol. 1985;48(1):18-34.

47. Critchlow B. The powers of John Barleycorn: beliefs about the effects of alcohol on social behavior. Am Psychol. 1986;41(7):751-764.

48. Meyer WU, Reisenzein R, Schützwohl A. Einführung in die Emotionspsychologie - Band I: Die Emotionstheorien von Watson, James, und Schachter. Bern: Hans Huber; 2001.

49. Holdstock L, King AC, de Wit H. Subjective and objective responses to ethanol in moderate/heavy and light social drinkers. Alcohol Clin Exp Res. 2000;24(6):789-794.

50. Kreusch F, Vilenne A, Quertemont E. Assessing the stimulant and sedative effects of alcohol with explicit and implicit measures in a balanced placebo design. J Stud Alcohol Drugs.2013;74(6):923-930.

51. Read JP, Wood MD, Lejuez CW, Palfai TP, Slack M. Gender, alcohol consumption, and differing alcohol expectancy dimensions in college drinkers. Exp Clin Psychopharmacol. 2004;12(4):298-308.

52. Morean ME, Corbin WR. Subjective response to alcohol: a critical review of the literature. Alcohol Clin Exp Res. 2010;34(3):385-395.

53. Moher D, Liberati A, Tetzlaff J, Altman DG. Preferred Reporting Items for Systematic Reviews and Meta-Analyses: the PRISMA statement. Open Med. 2009;3(3):123-130.

54. Fortunata M, Osório FL. Recognition of facial expressions by alcoholic patients: a systematic literature review. Neuropsychiatr Dis Treat. 2014;10:1655-1663.

55. Horn-Hofmann C, Büscher P, Lautenbacher S, Wolstein J. The effect of nonrecurring alcohol administration on pain perception in humans: a systematic review. J Pain Res. 2015;8:175-187.

56. Kun B, Demetrovics Z. Emotional intelligence and addictions: a systematic review. Subst Use Misuse. 2010;45(7-8):1131-1160.

57. Izard CE. The Maximally Discriminative Facial Movement Coding System (MAX) - Manual. Newark (NJ): University of Delaware; 1979.

58. Kushner MG, Massie ED, Gaskel S, Mackenzie T, Fiszdon J, Anderson N. Alcohol effects on the facial expressions of anxiety patients undergoing a panic provocation. Addict Behav. 1997;22(2): 275-280.

59. Weaver JB, Masland JL, Kharazmi S, Zillmann D. Effect of alcoholic intoxication on the appreciation of different types of humor. $J$ Pers Soc Psychol. 1985;49(3):781-787. 
60. Glautier S, O’Brien J, Dixon J. Facial electromyographic (EMG) responses to emotionally significant visual images: differences between light and heavy drinkers. Drug Alcohol Depend. 2001;64(3):337-345.

61. Sayette MA, Martin CS, Wertz JM, Perrott MA, Peters AR. The effects of alcohol on cigarette craving in heavy smokers and tobacco chippers. Psychol Addict Behav. 2005;19(3):263-270.

62. Sayette MA, Smith DW, Breiner MJ, Wilson GT. The effect of alcohol on emotional response to a social stressor. J Stud Alcohol. 1992;53(6):41-545.

63. Sayette MA, Martin CS, Perrott MA, Wertz JM, Hufford MR. A test of the appraisal-disruption model of alcohol and stress. $J$ Stud Alcohol. 2001;62(2):247-256.

64. Kirchner TR, Sayette MA, Cohn JF, Moreland RL, Levine JM. Effects of alcohol on group formation among male social drinkers. J Stud Alcohol. 2006;67(5):785-793.

65. Parrott DJ, Gallagher KE, Zeichner A. Liquid courage or liquid fear: alcohol intoxication and anxiety facilitate physical aggression. Subst Use Misuse. 2012;47(7):774-786.

66. Parrott DJ, Zeichner A, Stephens D. Effects of alcohol, personality, and provocation on the expression of anger in men: a facial coding analysis. Alcohol Clin Exp Res. 2003;27(6):937-945.

67. Ruch W. Extraversion, alcohol, and enjoyment. Pers Individ Dif. 1993;16(1):89-102.

68. Ruch W. Will the real relationship between facial expression and affective experience please stand up: the case of exhilaration. Cogn Emot. 1995;9(1):33-58.

69. Parks KA, Hequembourg AL, Dearing RL. Women's social behavior when meeting new men: the influence of alcohol and childhood sexual abuse. Psychol Women Q. 2008;32(2):145-158.

70. Samp JA, Monahan JL. Alcohol-influenced nonverbal behaviors during discussions about a relationship problem. J Nonverbal Behav. 2009;33(3):193-211.

71. Fairbairn CE, Sayette MA, Aalen OO, Frigessi A. Alcohol and emotional contagion an examination of the spreading of smiles in male and female drinking groups. Clin Psychol Sci. 2015;3(5):686-701.

72. Sayette MA, Creswell KG, Dimoff JD, et al. Alcohol and group formation: a multimodal investigation of the effects of alcohol on emotion and social bonding. Psychol Sci. 2012;(23):869-878.

73. Dimberg U, Thunberg M, Elmehed K. Unconscious facial reactions to emotional facial expressions. Psychol Sci. 2000;11(1):86-89.

74. Kring AM, Gordon AH. Sex differences in emotion: expression, experience, and physiology. J Pers Soc Psychol. 1998;74(3):686-703.

75. Kring MA. Gender and anger. In: Fischer AH, editor. Gender and Emotion. Cambridge: Cambridge University Press; 2002:211-231.

76. LaFrance M, Hecht MA, Paluck EL. The contingent smile: a meta-analysis of sex differences in smiling. Psychol Bull. 2003;129(2):305-334.

77. Manstead AS. Gender differences in emotion. In Gale A, Eysenck MW, editors. Handbook of Individual Differences: Biological Perspectives. Oxford: John Wiley \& Sons; 1992:355-387.

78. Timmers M, Fischer AH, Manstead AS. Gender differences in motives for regulating emotions. Pers Soc Psychol Bull. 1998;24(9):974-985.

79. Jones BT, Corbin W, Fromme K. A review of expectancy theory and alcohol consumption. Addiction. 2001;96(1):57-72.

80. Leigh BC, Stacy AW. Alcohol expectancies and drinking in different age groups. Addiction. 2004;99(2):215-227.

81. Addicott MA, Marsh-Richard DM, Mathias CW, Dougherty DM. The biphasic effects of alcohol: comparisons of subjective and objective measures of stimulation, sedation, and physical activity. Alcohol Clin Exp Res. 2007;31(11):1883-1890.
82. Söderlund H, Parker ES, Schwartz BL, Tulving E. Memory encoding and retrieval on the ascending and descending limbs of the blood alcohol concentration curve. Psychopharmacology. 2005;182(2):305-317.

83. Sutker PB, Tabakoff B, Goist KC, Randall CL. Acute alcohol intoxication, mood states and alcohol metabolism in women and men. Pharmacol Biochem Behav. 1983;18 (Suppl 1): 349-354.

84. Pishkin V, Lawrence BE, Bourne LE. Cognitive and electrophysiologic parameters during ascending and descending limbs of the blood alcohol curve. Alcohol Clin Exp Res. 1983;7(1):76-82.

85. Fairbairn CE, Sayette MA, Wright AG, Levine JM, Cohn JF, Creswell KG. Extraversion and the rewarding effects of alcohol in a social context. J Abnorm Psychol. 2015;124(3):660-673.

86. Fairbairn CE, Sayette MA. A social-attributional analysis of alcohol response. Psychol Bull. 2014;140(5):1361-1382.

87. Wirtz MA, editor. Dorsch: Lexikon der Psychologie. 18th ed. Bern: Hans Huber; 2017.

88. Kirkpatrick MG, de Wit H. In the company of others: social factors alter acute alcohol effects. Psychopharmacology. 2013;230(2):215-226.

89. Larsen JT, Norris CJ, Cacioppo JT. Effects of positive and negative affect on electromyographic activity over zygomaticus major and corrugator supercilii. Psychophysiology. 2003;40(5):776-785.

90. Sayette MA, Wertz JM, Martin CS, Cohn JF, Perrott MA, Hobel J. Effects of smoking opportunities on cue-elicited urge: a facial coding analysis. Exp Clin Psychopharmacol. 2003;11(3):218-227.

91. Stevens S, Cludius B, Bantin T, Hermann C, Gerlach AL. Influence of alcohol on social anxiety: an investigation of attentional, physiological and behavioral effects. Biol Psychol. 2014;96:126-133.

92. Fairbairn CE, Sayette MA. The effect of alcohol on emotional inertia: a test of alcohol myopia. J Abnorm Psychol. 2013;122(3):770-781.

93. Fairbairn CE, Sayette MA, Levine JM, Cohn JF, Creswell KG. The effects of alcohol on the emotional displays of whites in interracial groups. Emotion. 2013;13(3):468-477.

94. Bischof-Köhler D. Von Natur aus Anders: Die Psychologie der Geschlechtsunterschiede. Stuttgart: Kohlhammer; 2006.

95. Giancola PR, Zeichner A. An investigation of gender differences in alcohol-related aggression. $J$ Stud Alcohol. 1995;56(5):573-579.

96. Levenson JL, McClish DK, Dahman BA, et al. Alcohol abuse in sickle cell disease: the PiSCES project. Am J Addict. 2007;16(5):383-388.

97. Sheu R, Lussier D, Rosenblum A, et al. Prevalence and characteristics of chronic pain in patients admitted to an outpatient drug and alcohol treatment program. Pain Med. 2008;9(7):911-917.

98. Thompson T, Oram C, Correll CU, Tsermentseli S, Stubbs B. Analgesic effects of alcohol: a systematic review and meta-analysis of controlled experimental studies in healthy participants. J Pain. 2017;18(5):499-510.

99. Bartley EJ, Rhudy JL. The influence of pain catastrophizing on experimentally induced emotion and emotional modulation of nociception. J Pain. 2008;9(5):388-396.

100. De Wied M, Verbaten MN. Affective pictures processing, attention, and pain tolerance. Pain. 2001;90(1):163-172.

101. Kamping S, Bomba I, Kanske P, Diesch E, Flor H. Deficient modulation of pain by a positive emotional context in fibromyalgia patients. Pain. 2013;154(9):1846-1855.

102. Kenntner-Mabiala R, Weyers P, Pauli P. Independent effects of emotion and attention on sensory and affective pain perception. Cogn Emot. 2007;21(8):1615-1629.

103. Roy M, Piché M, Chen JI, Peretz I, Rainville P. Cerebral and spinal modulation of pain by emotions. Proc Natl Acad Sci U S A. 2009;106(49):20900-20905. 
Psychology Research and Behavior Management is an international, peerreviewed, open access journal focusing on the science of psychology and its application in behavior management to develop improved outcomes in the clinical, educational, sports and business arenas. Specific topics covered in the journal include: Neuroscience, memory and decision making; Behavior modification and management; Clinical applications; Business and sports performance management; Social and developmental studies; Animal studies. The manuscript management system is completely online and includes a very quick and fair peer-review system, which is all easy to use. Visit http://www. dovepress.com/testimonials.php to read real quotes from published authors.

Submit your manuscript here: https://www.dovepress.com/psychology-research-and-behavior-management-journal 